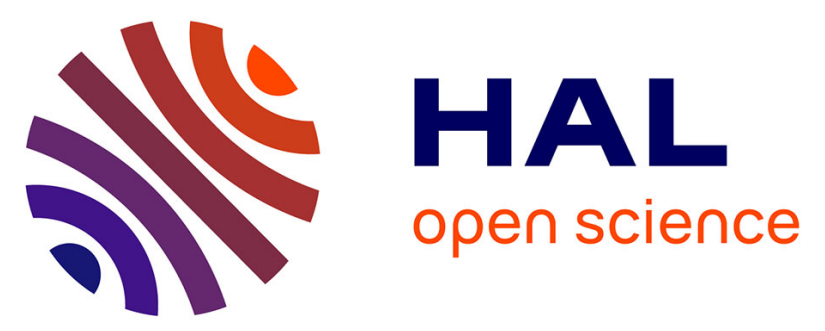

\title{
Extubation Success Prediction in a Multicentric Cohort of Patients with Severe Brain Injury
}

Karim Asehnoune, Philippe Seguin, Sigismond Lasocki, Antoine Roquilly, Adrien Delater, Antoine Gros, Florian Denou, Pierre-Joachim Mahé, Nicolas Nesseler, Dominique Demeure-Dit-Latte, et al.

\section{To cite this version:}

Karim Asehnoune, Philippe Seguin, Sigismond Lasocki, Antoine Roquilly, Adrien Delater, et al.. Extubation Success Prediction in a Multicentric Cohort of Patients with Severe Brain Injury. Anesthesiology, 2017, 127 (2), pp.338-346. 10.1097/ALN.0000000000001725 . hal-01760471

\section{HAL Id: hal-01760471 \\ https://hal.science/hal-01760471}

Submitted on 11 Dec 2019

HAL is a multi-disciplinary open access archive for the deposit and dissemination of scientific research documents, whether they are published or not. The documents may come from teaching and research institutions in France or abroad, or from public or private research centers.
L'archive ouverte pluridisciplinaire HAL, est destinée au dépôt et à la diffusion de documents scientifiques de niveau recherche, publiés ou non, émanant des établissements d'enseignement et de recherche français ou étrangers, des laboratoires publics ou privés. 


\title{
Extubation Success Prediction in a Multicentric Cohort of Patients with Severe Brain Injury
}

\author{
Karim Asehnoune, M.D., Ph.D., Philippe Seguin, M.D., Ph.D., Sigismond Lasocki, M.D., Ph.D., \\ Antoine Roquilly, M.D., Ph.D., Adrien Delater, M.D., Antoine Gros, M.D., Florian Denou, M.D., \\ Pierre-Joachim Mahé, M.D., Nicolas Nesseler, M.D., Dominique Demeure-dit-Latte, M.D., \\ Yoann Launey, M.D., Karim Lakhal, M.D., Bertrand Rozec, M.D., Ph.D., Yannick Mallédant, M.D., Ph.D., \\ Véronique Sébille, Ph.D., Samir Jaber, M.D., Ph.D., Aurélie Le Thuaut, M.Sc., Fanny Feuillet, Ph.D., \\ Raphaël Cinotti, M.D.; ATLANREA group*
}

\section{ABSTRACT}

Background: Patients with brain injury are at high risk of extubation failure.

Methods: We conducted a prospective observational cohort study in four intensive care units of three university hospitals. The aim of the study was to create a score that could predict extubation success in patients with brain injury.

Results: A total of 437 consecutive patients with brain injury were included, and 338 patients (77.3\%) displayed successful extubation. In the multivariate analysis, four features were associated with success the day of extubation: age less than $40 \mathrm{yr}$, visual pursuit, swallowing attempts, and a Glasgow coma score greater than 10. In the score, each item counted as one. A score of 3 or greater was associated with $90 \%$ extubation success. The area under the receiver-operator curve was $0.75(95 \%$ $\mathrm{CI}, 0.69$ to 0.81$)$. After internal validation by bootstrap, the area under the receiver-operator curve was 0.73 ( $95 \% \mathrm{CI}, 0.68$ to 0.79 ). Extubation success was significantly associated with shorter duration of mechanical ventilation (11 [95\% CI, 5 to 17 days] vs. 22 days [95\% CI, 13 to 29 days]; $P<0.0001$ ), shorter intensive care unit length of stay (15 [95\% CI, 9 to 23 days] vs. 27 days [95\% CI, 21 to 36 days]; $P<0.0001)$, and lower in-intensive care unit mortality (4 [1.2\%] vs. 11 [11.1\%]; $P<0.0001)$.

Conclusions: Our score exploring both airway functions and neurologic status may increase the probability of successful extubation in patients with severe brain injury.

$\mathbf{P}$ ROLONGED mechanical ventilation (MV) is common in patients with severe brain injury (BI), and improvement in the outcome of patients with mechanically ventilated BI could have major medical and economic implications. ${ }^{1}$ The extubation decision process is challenging in patients with severe BI because both extubation failure and delayed extubation are common in this population, increasing morbidity and mortality. In particular, delayed extubation leads to ventilator-associated pneumonia (VAP) without decreasing the risk of extubation failure. ${ }^{2}$ The prevention of delayed extubation is therefore one of the most promising intervention targets for improving outcome. No recommendation exists for extubation in patients with BI because these patients are excluded from the current guidelines. ${ }^{3}$ The usual predictors of successful extubation when patients had passed a spontaneous breathing trial (SBT) do not apply because the ability to protect the airway and the neurologic status are both impaired.

In daily practice, extubation is usually left to the discretion of the physician; we therefore prospectively assessed the relationship between simple clinical variables and extubation success. Our specific aim was to develop a clinical score predicting successful extubation in patients with $\mathrm{BI}$ as the

rate of VAP increases greatly when extubation is delayed. ${ }^{1,4}$ We also compared the outcomes of patients with success or failure of the extubation process. Primary results of the study 
were presented during the 2012 Congress of the French Society of Anesthesiology and Critical Care Medicine.

\section{Materials and Methods}

\section{Study Population and Setting}

The study was performed in four surgical intensive care units (ICUs) of three university hospitals from January 2011 to June $2014 .^{5}$ The study protocol was approved by the local ethics committee of Nantes (Groupe Nantais d'Ethique dans le Domaine de la Santé, Nantes, France). Because the study was purely observational, consent was waived. Written information was delivered to the patient's next of kin and to the patient when neurologic recovery was deemed appropriate.

\section{Inclusion}

Adult patients (older than $18 \mathrm{yr}$ ) with primary BI such as traumatic brain injury (TBI), aneurysmal subarachnoid hemorrhage (SAH), intracerebral hemorrhage, malignant stroke, central nervous system infection, and brain tumor; with an initial Glasgow coma score (GCS) of 12 or less; and whose duration of MV was $48 \mathrm{~h}$ or more, were eligible. Consecutive patients undergoing scheduled or unplanned extubation were included.

\section{Noninclusion Criteria}

Patients were not included when extubation was performed in the context of critical care withdrawal, pregnancy, or spine cord injury above T4.

\section{General ICU Management}

Neuro-ICU management was carried out according to international guidelines. ${ }^{6-8}$ Sedation was administered in patients with BI to control intracranial pressure (when available), oxygenation, and capnia, and to prevent aspiration. ${ }^{9}$ Initial sedation was performed with midazolam, and thiopental was used only in the case of refractory intracranial hypertension. ${ }^{1,10,11}$ Daily interruption of sedation was not performed in the participating ICUs. ${ }^{12}$ After initial neuro-ICU

Submitted for publication September 14, 2016. Accepted for publication March 16, 2017. From the Intensive Care Unit, Anesthesia and Critical Care Department, Hôtel Dieu (K.A., A.R, A.D., P.J.M., D.D.-d.-L., R.C.), Laboratoire UPRES EA 3826, Thérapeutiques Cliniques et Expérimentales des Infections (K.A., A.R.), Institut du Thorax, Institut National de la Santé et de la Recherche Médicale UMR1087 IRT (B.R.), EA 4275 SPHERE, Methods for Patients-centered Outcomes and Health Research, UFR des Sciences Pharmaceutiques (V.S., F.F.), and Plateforme de Biométrie, Cellule de Promotion de la Recherche Clinique (V.S., A.L.T., F.F.), University Hospital of Nantes, Nantes, France; Intensive Care Unit, Anesthesia and Critical Care Department, Hôpital Pontchaillou, University Hospital of Rennes, Rennes, France (P.S., N.N., Y.L, Y.M.); Intensive Care Unit, Anesthesia and Critical Care Department, University Hospital of Angers, Angers, France (S.L., A.G., F.D.); Intensive Care Unit, Anesthesia and Critical Care Department, Hôpital Laennec, University Hospital of Nantes, Saint-Herblain, France (K.L., B.R.); and Intensive Care Unit, Anesthesia and Critical Care Department, Saint Eloi University Hospital of Montpellier, Montpellier, France (S.J.). management and after brain computed tomography scan control, continuous sedation was stopped. In participating ICUs, enteral nutrition was started in the first $48 \mathrm{~h}$ after admission, with an objective of 20 to $30 \mathrm{kcal} \cdot \mathrm{kg}^{-1} \cdot$ day $^{-1} 13$ in the first 5 days; residual gastric volume evaluation was not performed; and vomiting episodes were treated with metoclopramide for 48 to $72 \mathrm{~h}$. Postextubation stridor prevention was left to the discretion of the physician.

\section{Weaning Protocol}

Participating ICUs used and followed weaning protocols described in the international guidelines. ${ }^{3}$ All of the patients were checked daily, at least once, by the attending physician according to predefined weaning criteria: (1) motor component of the GCS 4 or higher without continuous sedation; (2) stable cardiovascular status (heart rate 140 beats/min or less, systolic blood pressure 90 to $160 \mathrm{mmHg}$, and minimal or absence of catecholamine; (3) adequate oxygenation (oxygen saturation measured by pulse oximetry $\left[\mathrm{Spo}_{2}\right] 90 \%$ or higher, fractional inspired oxygen tension of $40 \%$ or lower, positive end-expiratory pressure of $8 \mathrm{~cm} \mathrm{H} \mathrm{H}_{2} \mathrm{O}$ or lower, respiratory rate of 35 breaths/min or less); (4) $\mathrm{PaCO}_{2}$ of $50 \mathrm{mmHg}$ or lower; (5) core temperature less than $38.5^{\circ} \mathrm{C}$; and (6) $\mathrm{pH}$ of 7.35 or higher. SBT was systematically performed in all of the patients included, and because the latest conference of consensus did not clearly recommend one method over the other, the physician could either perform a 30-min T-tube trial or ventilatory support level less than or equal to 7 to $8 \mathrm{~cm} \mathrm{H}_{2} \mathrm{O} .{ }^{3}$ Maximal inspiratory pressure, maximal expiratory pressures, and maximal expiratory flow were not routine in participating centers. Failure of the weaning test was defined as the development within $30 \mathrm{~min}$ of any of the following criteria: respiratory rate of 35 breaths/min or higher with increased accessory muscle activity, $\mathrm{SpO}_{2}$ less than $90 \%$ (on fractional inspired oxygen tension $=0.4$, heart rate greater than 140 beats $/ \mathrm{min}$, systolic blood pressure less than $90 \mathrm{mmHg}$ or greater than 180 $\mathrm{mmHg}$, major dyspnea or agitation, or GCS of 8 or less. ${ }^{3,8}$ All of the patients included underwent successful SBT.

\section{Extubation Protocol}

One hour before extubation, a standardized physical examination with 26 items was performed by the attending physician (Supplemental Digital Content 1, items of the physical examination before extubation, http://links.lww.com/ALN/ B489). To build this standardized checklist, we selected variables based on our clinical expertise and from studies in the literature. Cuff-leak test performance was left to the discretion of the physician. The endotracheal tube was then removed in the presence of a physiotherapist. After extubation, oxygenation was optimized with oxygen masks to reach an $\mathrm{SpO}_{2}$ greater than or equal to 94 to $95 \%$. After extubation, prophylactic noninvasive ventilation and highflow oxygen nasal therapy were not performed. In case of an unplanned extubation, the standardized examination was 
to extubation. In case of postextubation respiratory failure, physiotherapy was performed but not noninvasive ventilation because of the risk of aspiration in patients with variable levels of consciousness. Patients were reintubated if they met at least one of the following conditions: severe respiratory failure (respiratory rate more than 40 breaths/min and $\mathrm{SpO}_{2}$ less than $90 \%$ despite oxygen supplementation), neurologic impairment (GCS of 8 or less), or hemodynamic failure (heart rate greater than 140 beats/min and systolic blood pressure of $80 \mathrm{mmHg}$ or lower).

\section{Primary Outcome Variable}

The primary outcome variable was extubation success, after the first extubation attempt. The time interval used to define extubation failure remains a matter of debate (from $48 \mathrm{~h}$ to 7 days). Because noninvasive ventilation was not used in the postextubation period and could not delay reintubation, extubation failure was defined as the need for reintubation in the first $48 \mathrm{~h}$ after extubation. ${ }^{3,14}$ During the study period, tracheostomy was not performed during the first 7 days of the ICU course. Tracheostomy was considered after several days of sedation discontinuation with low blood dosages of sedatives, in the context of long-term impaired consciousness (GCS of 8 or less). These patients who never underwent extubation attempt and received late tracheostomy were a priori considered to have a neurologic cause of extubation failure. We performed two sensitivity analyses by excluding patients who underwent late tracheostomy and patients who failed extubation due to postextubation stridor. Extubation failure cause was recorded by the physician performing reintubation according to a list of predefined causes: neurologic failure, respiratory failure, postextubation stridor, or cardiovascular failure.

\section{Secondary Outcome Variable}

VAP, duration of MV, ICU length of stay, and in-ICU mortality were monitored. The causes for extubation failure were recorded and were a priori defined. The consequences of extubation failure were also evaluated. Patient follow-up ended on ICU discharge.

\section{Statistical Analysis}

Our primary analysis was to explore the factors associated with extubation success as stated in the primary outcome variable. Univariate analysis was conducted to determine the potential factors associated with extubation success. Variables identified by univariate analysis with a cutoff at 0.20 were included in a multivariate logistic regression model, and backward selection was applied. A Hosmer-Lemeshow test was used to test calibration of the model. The final model was presented with the crude odds ratio (OR) and 95\% CI. The ability of the model to discriminate participants with or without extubation success was quantified by using the area under the receiver-operating characteristic curve (AUC). In the final regression analysis model, 12 variables were selected number of events recorded (99 extubation failures). For continuous variables, the best threshold was chosen according to the best sensitivity, specificity, positive predictive value, negative predictive value, and Youden index. Power calculation is not available because the items studied have not been explored in the literature.

The internal validity of the regression model was assessed using bootstrapping techniques: random samples, with replacement, were taken 1,000 times from the study population. ${ }^{15}$ The outcome was a correction factor for the AUC to correct for statistical overoptimism AUC.

The VISAGE score (visual pursuit, swallowing, age, Glasgow for extubation) based on the four factors identified was constructed to include patients under $40 \mathrm{yr}$ of age, presence of visual pursuit, swallowing attempts, and GCS greater than 10 . One point was attributed for each factor from the regression model, because we considered that their OR values were similar. For consecutive cutoffs of the sum scores, sensitivity, specificity, negative positive predictive values, and likelihood ratio were calculated.

We performed two sensitivity analyses. First, we excluded patients who underwent late tracheostomy and only kept patients requiring intubation $48 \mathrm{~h}$ after extubation in the analysis, as defined in the last consensus conference. ${ }^{3}$ Second, we excluded patients with postextubation stridor requiring reintubation, which is not specific to this population. Two imputation analyses were performed for patients with missing data. In the first one, we assumed that all of the missing items were not present. In the second one, we assumed that all of the missing items were present. A decision curve analysis was also performed to evaluate the net benefit of extubation decision with the VISAGE score. ${ }^{16}$

Continuous data are expressed as mean \pm SD or median ( $25^{\text {th }}$ to $75^{\text {th }}$ percentiles) and tested with a $t$ test for parametric or Wilcoxon test for nonparametric data accordingly. Categoric data are expressed as numbers and percentages and tested with chi-square test or Fisher test. The significance level was set at a $P \leq 0.05$. Statistical analysis was performed using SAS statistical software (version 9.3, SAS Institute, USA).

\section{Results}

\section{Study Cohort}

A total of 437 patients were included in the study: 186 TBI (42.6\%), $126 \mathrm{SAH}(28.8 \%), 54$ intracerebral hemorrhage (12.4\%), 22 malignant stroke (5\%), and 49 miscellaneous pathologies (11.2\%; Supplemental Digital Content 2, flowchart of the study, http://links.lww.com/ALN/B490). The overall population characteristics are shown in table 1 . The median GCS before ICU admission was seven (range, 5 to 10). We recorded 99 extubation failures (22.6\%). The causes of BI and baseline GCS were not different between the extubation failure group and extubation success group (table 1). Patients with extubation failure had a higher Simplified Acute 


\begin{tabular}{|c|c|c|c|c|}
\hline & $\begin{array}{l}\text { Overall Population, } \\
\qquad N=437\end{array}$ & $\begin{array}{c}\text { Patients with } \\
\text { Extubation Success, } \\
\mathrm{N}=338(77.4 \%)\end{array}$ & $\begin{array}{c}\text { Patients with } \\
\text { Extubation Failure, } \\
N=99(22.6 \%)\end{array}$ & $P$ Value \\
\hline Cause of brain injury, $\mathrm{n}(\%)$ & & & & 0.4 \\
\hline TBI & $186(42.6)$ & $151(44.7)$ & $35(35.3)$ & \\
\hline $\mathrm{SAH}$ & $126(28.8)$ & $97(28.7)$ & 29 (29.3) & \\
\hline $\mathrm{ICH}$ & $54(12.4)$ & $39(11.5)$ & $15(15.1)$ & \\
\hline Stroke & $22(5)$ & $16(4.7)$ & $6(6)$ & \\
\hline Other & $49(11.2)$ & $35(10.4)$ & $14(14.3)$ & \\
\hline Sex: male/female, n (\%) & $267(61.1) / 170(38.9)$ & $206(60.9) / 132(39.1)$ & $61(61.6) / 38(38.4)$ & 0.9 \\
\hline Age, mean \pm SD & $50 \pm 18$ & $48 \pm 18$ & $54 \pm 18$ & 0.0037 \\
\hline Age < 40 yr, n (\%) & $130(29.7)$ & $111(33)$ & 19 (19) & 0.009 \\
\hline Body mass index, mean \pm SD & $25 \pm 5$ & $25 \pm 5$ & $25 \pm 4$ & 0.5 \\
\hline SAPS II, mean \pm SD & $42 \pm 12$ & $41 \pm 12$ & $44 \pm 14$ & 0.04 \\
\hline $\begin{array}{l}\text { Initial GCS at ICU admission, median } \\
\left(25^{\text {th }} \text { to } 75^{\text {th }} \text { percentiles }\right)\end{array}$ & $7(5-10)$ & $7(5-10)$ & $7(3-10)$ & $0.15^{*}$ \\
\hline $\mathrm{NYHA} \geq 2, \mathrm{n}(\%)$ & $24(5.5)$ & $20(6)$ & $4(4)$ & 0.4 \\
\hline Chronic respiratory disease, n (\%) & $30(6.9)$ & $22(6.6)$ & $8(8.2)$ & 0.5 \\
\hline Diabetes mellitus, $\mathrm{n}(\%)$ & $33(7.6)$ & $21(6.3)$ & $12(12.1)$ & 0.05 \\
\hline Active smoking, $n(\%)$ & $112(25.6)$ & $87(27)$ & $25(26.6)$ & 0.9 \\
\hline Craniotomy on admission, $\mathrm{n}(\%)$ & $98(22.4)$ & $77(26.6)$ & $21(23.3)$ & 0.5 \\
\hline External ventricular drainage, $\mathrm{n}(\%)$ & $134(30.7)$ & $98(34)$ & $36(41.4)$ & 0.2 \\
\hline Decompressive craniectomy, n (\%) & $38(8.7)$ & $32(9.5)$ & $6(6.2)$ & 0.3 \\
\hline
\end{tabular}

Continuous data are expressed as mean \pm SD or median ( $25^{\text {th }}$ to $75^{\text {th }}$ percentiles) accordingly and categoric data are expressed as $\mathrm{n}$ (\%) and tested with the Fisher test. $P<0.2$ is considered as statistically significant and tested in the multivariate analysis for the elaboration of the prediction score.

*Data were tested with a Wilcoxon test.

GCS = Glasgow coma score; $I \mathrm{CH}=$ intracerebral hemorrhage; ICU = intensive care unit; NYHA = New York Heart Association; SAH = subarachnoid hemorrhage; SAPS = Simplified Acute Physiologic Score; TBI = traumatic brain injury.

extubation success (table 1). At the time of extubation, GCS was higher in the extubation success group than in the extubation failure group (11 [10 to 14] vs. 11 [9 to 13$] ; P<0.0001$ ). There was a difference between the GCS eye component ( 4 [ 4 to 4 ] vs. 4 [3 to 4]; $P=0.008$ ) and the GCS motor component (6 [6 to 6] vs. $6[5$ to 6]; $P<0.0001$ ) but not the verbal component (table 2; Supplemental Digital Content 3, GCS ranges in the group of extubation success and failure, http://links. lww.com/ALN/B491). The reasons for extubation failure were neurologic impairment $(n=36[36.3 \%])$, hypoxemia $(n=33$ [33.3\%]), unmanageable endotracheal secretions $(n=50$ [50.5\%]), respiratory failure $(\mathrm{n}=17$ [17.1\%]), cardiovascular failure $(n=1[1 \%])$, and postextubation stridor $(n=19$ [19.2\%]). Four patients (4\%) displayed both neurologic and respiratory failure; 14 patients (14.1\%) displayed neurologic impairment along with unmanageable endotracheal secretions. The duration of the SBT was not different between the intubation success and intubation failure groups (table 2). Twenty patients (4.6\%) displayed accidental extubation. All of these patients underwent successful SBT. Among them, 15 patients $(75 \%)$ were not reintubated.

\section{Univariate Analysis: Selection of the Potential Factors Associated with Extubation Success}

In univariate analysis, the factors associated with extubation success were patient age, Simplified Acute Physiologic Score II, the presence of leak during a cuff-leak test, visual pursuit, absence of hypotonia, motor component of the GCS and total GCS, vomiting episodes, agitation requiring physical contention, patient attempts to rip the endotracheal tube out, and administration of morphine or corticosteroids for postextubation stridor prevention (table 2). These criteria were kept in the multivariate analysis.

\section{Multivariate Analysis: Factors Independently Associated with Extubation Success}

In multivariate analysis, factors independently associated with a successful extubation were, age less than $40 \mathrm{yr}$ $(\mathrm{OR}=2.27$ [95\% CI, 1.21 to 4.26]; $P=0.0109)$, presence of visual pursuit ( $\mathrm{OR}=2.79$ [95\% CI, 1.61 to 4.82]; $P=0.0002$ ), attempts of swallowing (spontaneous and/ or on demand; $\mathrm{OR}=2.90$ [95\% CI, 1.67 to 5.03$] ; P=$ $0.0001)$, and total GCS greater than $10(\mathrm{OR}=2.40[95 \%$ CI, 1.38 to 4.18 ]; $P=0.0019$ ). For age, the threshold age less than $40 \mathrm{yr}$ displayed a sensitivity of $47.4 \%$, a specificity of $67.1 \%$, a positive predictive value of $29.7 \%$, a negative predictive value of $81.3 \%$, and a Youden index of $14.6 \%$. GCS threshold predicting extubation success was upheld according to the higher Youden index. The threshold greater than 10 displayed a sensitivity of $47.4 \%$, a specificity of $75 \%$, a positive predictive value of $35.9 \%$, a negative predictive value of $82.8 \%$, and a Youden index of $22.4 \%$. The Hosmer-Lemeshow test 
Table 2. Comparison of the Clinical Variables Collected on the Day of Extubation in Patients with Extubation Success and Extubation Failure

\begin{tabular}{|c|c|c|c|}
\hline Clinical Evaluation & $\begin{array}{l}\text { Extubation Success, } \\
\qquad N=338\end{array}$ & $\begin{array}{l}\text { Extubation Failure, } \\
\qquad \mathrm{N}=99\end{array}$ & $P$ Value \\
\hline $\begin{array}{l}\text { T-tube breathing duration in the previous } 24 \mathrm{~h} \text {, median }\left(25^{\text {th }}-75^{\text {th }}\right. \\
\text { percentiles }), h\end{array}$ & $1(0-2.5)$ & $1(0-2.0)$ & 0.2 \\
\hline Endotracheal suctioning $<2 / \mathrm{h}, \mathrm{n}(\%)$ & $185(55.4)$ & $53(54.6)$ & 0.9 \\
\hline Leak presence with cuff-leak test, $\mathrm{n}(\%)$ & $52(16.2)$ & $8(8.42)$ & 0.004 \\
\hline Glasgow coma score, median ( $25^{\text {th }}-75^{\text {th }}$ percentiles) & $11(10-14)$ & $11(9-13)$ & $<0.0001$ \\
\hline Eye score, median $\left(25^{\text {th }}-75^{\text {th }}\right.$ percentiles $)$ & $4(4-4)$ & $4(3-4)$ & 0.008 \\
\hline Verbal score, median $\left(25^{\text {th }}-75^{\text {th }} \text { percentiles }\right)^{*}$ & $2(1-4)$ & $1(1-4)$ & 0.02 \\
\hline Motor score, median $\left(25^{\text {th }}-75^{\text {th }}\right.$ percentiles) & $6(6-6)$ & $6(5-6)$ & $<0.0001$ \\
\hline Positive answers to simple questions, $\mathrm{n}(\%)$ & $240(71.8)$ & $66(67.3)$ & 0.4 \\
\hline Visual pursuit, n (\%) & $250(78.1)$ & $50(51.1)$ & $<0.0001$ \\
\hline Presence of cough, $\mathrm{n}(\%)$ & $283(87)$ & $80(84.2)$ & 0.4 \\
\hline Swallowing attempts, $\mathrm{n}(\%)$ & $231(78.6)$ & $46(52.9)$ & $<0.0001$ \\
\hline Excessive presence of saliva requiring nursing, $n(\%)$ & $115(34.7)$ & $38(40.7)$ & 0.3 \\
\hline Vomiting episodes, n (\%) & $60(17.9)$ & $8(8.1)$ & 0.01 \\
\hline Constipation, $\mathrm{n}(\%)$ & 65 (19.5) & $18(18.7)$ & 0.9 \\
\hline Presence of hypotonia, $\mathrm{n}(\%)$ & $76(22.6)$ & $41(41.8)$ & 0.0002 \\
\hline Confusion, $\mathrm{n}(\%)$ & $86(25.9)$ & $20(21)$ & 0.3 \\
\hline Agitation requiring physical contention, $\mathrm{n}(\%)$ & $103(30.6)$ & $15(15.8)$ & 0.004 \\
\hline Patient attempts to rip the endotracheal tube out, $\mathrm{n}(\%)$ & $146(46.3)$ & $26(28)$ & 0.001 \\
\hline \multicolumn{4}{|l|}{ Medication with: } \\
\hline Neuroleptic, n (\%) & $34(10)$ & $7(7)$ & 0.4 \\
\hline Benzodiazepine, n (\%) & $38(11.2)$ & $8(8.1)$ & 0.4 \\
\hline Morphine or associated, n (\%) & $39(11.5)$ & $4(4)$ & 0.02 \\
\hline Corticosteroids (prevention of postextubation stridor), $\mathrm{n}(\%)$ & $34(10.1)$ & $3(3)$ & 0.02 \\
\hline
\end{tabular}

Univariate analysis of the clinical variables associated with extubation success. The clinical features were assessed on the day of extubation. The items collected are detailed in Supplemental Digital Content 1 (http://links.Iww.com/ALN/B489). Continuous data are expressed as mean \pm SD or median (25 th to $75^{\text {th }}$ percentiles) accordingly and tested with a paired $t$ test. Categoric data are expressed as $n$ (\%) and tested with the Fisher test. $P<0.2$ is considered as statistically significant and tested in the multivariate analysis for the elaboration of the prediction score.

*See Supplemental Digital Content 1 (http://links.Iww.com/ALN/B489) for verbal score definition.

indicated an adequate goodness of fit $(P=0.7703)$. The model correctly discriminated patients with or without extubation success, with an AUC of 0.75 (95\% CI, 0.69 to 0.81 ; table 3 ). Internal validation showed optimism in the AUC of 0.02 , resulting in a correction of the AUC of 0.73 ( $95 \% \mathrm{CI}, 0.68$ to 0.79 ).

\section{Elaboration of a Score Predictive of Extubation Success}

The VISAGE score based on the four factors identified was constructed as follows: patients under 40 years of age, presence of visual pursuit, swallowing attempts, and GCS greater than 10 . The characteristics of the score are provided in table 4. To evaluate the clinical significance of each factor taken separately and their combination, we investigated the rate of extubation success according to the number of factors and total score (fig. 1). The rate of extubation success was $23 \%$ in patients with a VISAGE score of zero, $56 \%$ with a score of 1 , and was significantly higher in patients with a score of 2 or 3 (70 to $90 \%)$. A VISAGE score greater or equal to 3 predicted extubation success with a sensitivity of $62 \%$, a specificity of $79 \%$, a positive predictive value of $90 \%$, a negative predictive value of $39 \%$, a positive likelihood ratio of 2.9 , and a negative likelihood ratio of 0.5 .

\section{Sensitivity Analyses}

The two sensitivity analyses performed revealed the same results. First, when patients who underwent late tracheostomy $(\mathrm{n}=40[40.4 \%])$ were excluded, the factors associated with extubation success in multivariate analysis were: age less than $40 \mathrm{yr}(\mathrm{OR}=5.03$ [95\% CI, 1.89 to 13.42$] ; P=0.0012)$, visual pursuit $(\mathrm{OR}=1.93[95 \% \mathrm{CI}, 0.99$ to 3.74$] ; P=0.052)$, swallowing attempts $(\mathrm{OR}=2.27$ [95\% CI, 1.17 to 4.41$] ; P=$ $0.01)$, and GCS greater than $10(\mathrm{OR}=2.32[95 \% \mathrm{CI}, 1.21$ to 4.47]; $P=0.01$ ). Patients undergoing late tracheostomy displayed persistent neurologic impairment (median GCS = 10 [range, 8 to 13]), 15 (43\%) displayed swallowing attempts and $16(40 \%)$ displayed visual pursuit.

Second, when patients with postextubation stridor ( $\mathrm{n}=19$ [19.2\%]), regarded as airway cause of extubation failure were excluded, the factors associated with extubation success in multivariate analysis were: age less than $40 \mathrm{yr}(\mathrm{OR}=2.27[95 \%$ CI, 1.14 to 4.52$] ; P=0.019$ ), visual pursuit $(\mathrm{OR}=3.18$ [95\% CI, 1.76 to 5.76]; $P=0.0001)$, swallowing attempts $(\mathrm{OR}=$ 3.19 [95\% CI, 1.76 to 5.79 ]; $P=0.0001$ ), and GCS greater than $10(\mathrm{OR}=2.87$ [95\% CI, 1.58 to 5.23 ]; $P=0.0006$; Supplemental Digital Content 4, sensitivity analyses with the exclusion of patients with postextubation stridor and tracheostomy, http://links.lww.com/ALN/B492). Finally, we tested the 
Table 3. Multivariate Analysis of Factors Associated with Extubation Success

\begin{tabular}{lrr}
\hline Clinical Features & OR $(95 \% \mathrm{Cl})$ & $P$ Value \\
\hline Age $(<40$ yr old $v s . \geq 40$ yr old $)$ & $2.27(1.21-4.26)$ & 0.0109 \\
Visual pursuit & $2.79(1.61-4.82)$ & 0.0002 \\
Swallowing attempts & $2.9(1.67-5.03)$ & 0.0001 \\
Glasgow coma score (10 vs. $\leq 10)$ & $2.4(1.38-4.18)$ & 0.0019 \\
\hline
\end{tabular}

Multivariate analysis of factors associated with extubation success. Age $<40 \mathrm{yr}$ is associated with more extubation success. The presence of visual pursuit, attempts of deglutition, and a Glasgow coma score $>10$ are associated with extubation success. $P<0.05$

$\mathrm{OR}=$ odds ratio

Table 4. VISAGE Score Calculation Worksheet

\begin{tabular}{lc}
\hline Extubation Success Score & $\begin{array}{c}\text { Assigned Points } \\
\text { According to Items }\end{array}$ \\
\hline Age $<40$ yr old (yes/no) & $1 / 0$ \\
Visual pursuit (yes/no) & $1 / 0$ \\
Swallowing attempts (yes/no) & $1 / 0$ \\
Glasgow coma score $>10$ (yes/no) & $1 / 0$ \\
\hline
\end{tabular}

VISAGE = visual pursuit, swallowing, age, Glasgow for extubation.

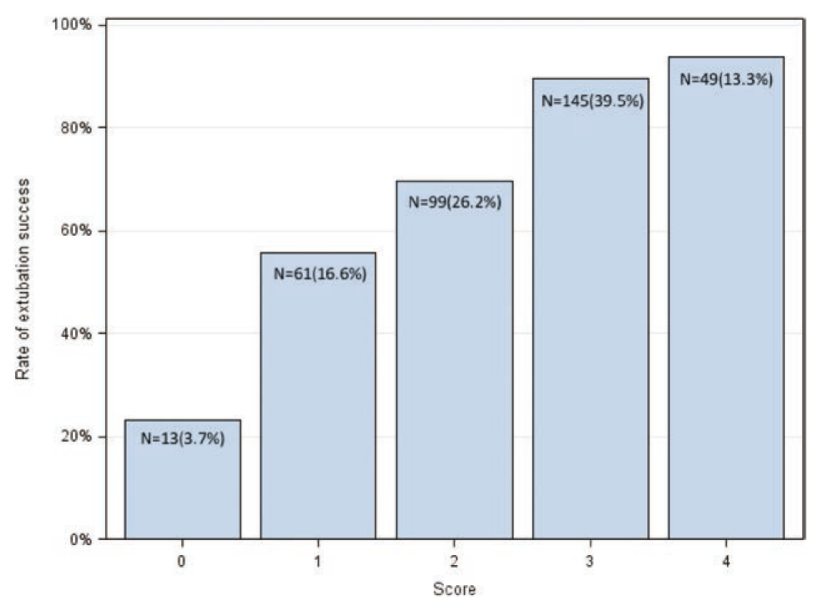

Fig. 1. Rate of extubation success according to the number of predictive factors.

clinical relevance of different GCS thresholds (Supplemental Digital Content 5, receiver-operator curves for age and GCS, http://links.lww.com/ALN/B493) and we tested our model in patients according to age ( 40 or older $v s$. less than $40 \mathrm{yr}$ ) and type of BI (TBI and SAH; Supplemental Digital Content 6, exploratory multivariate analysis in patients according to age and type of BI, http://links.lww.com/ALN/B494; Supplemental Digital Content 7, differences between centers and center effect in multivariate analysis, http://links.lww.com/ALN/ B495; Supplemental Digital Content 8, exploratory analysis excluding the verbal component of the GCS, http://links.lww. com/ALN/B496). Although some factors are not significant due to the loss of power, all ORs show the same trends.

\section{Decision Curve Analysis}

The decision curve analysis of the VISAGE score provides better net benefit than the alternate options (Supplemental Digital Content 9, decision curve analysis, http://links.lww. com/ALN/B497).

\section{Imputation Analysis for Missing Data}

Some data among the four items of the VISAGE score were not recorded for 70 patients. First, when at least one datum was missing among the following items: absence of visual pursuit, absence of swallowing attempts, or GCS of 10 or less, we substituted missing data with negative values. With this imputation, the multivariate analysis discriminated patients with or without extubation success with an AUC of 0.72 (range, 0.67 to 0.78 ). Second, we substituted missing data with positive values, and the multivariate analysis discriminated patients with or without extubation success with an AUC of 0.73 (range, 0.67 to 0.78; Supplemental Digital Content 10, imputation analyses for missing data, http:// links.lww.com/ALN/B498).

\section{Outcomes}

The median duration of MV was 12 days (range, 6 to 20 days) and median ICU length of stay was 17 days (range, 10 to 26 days). In univariate analysis, extubation success was associated with less in-ICU mortality, shorter duration of MV, and shorter ICU length of stay (table 5). Both sensitivity analyses displayed significantly lower morbidity (fewer days of MV and ICU length of stay) and lower in-ICU mortality in the group with extubation success (Supplemental Digital Content 11, morbidity and mortality of patients with extubation success when excluding postextubation stridor and tracheostomy, http://links.lww.com/ALN/B499; Supplemental Digital Content 12, morbidity and mortality in patients with tracheostomy, http:/links.lww.com/ ALN/B500; Supplemental Digital Content 13, extubation outcomes in patients with different GCS thresholds, http:// links.lww.com/ALN/B501).

\section{Discussion}

This study provides a user-friendly bedside score, the VISAGE score, which is associated with extubation success in patients with BI. This simple clinical rule combining four clinical variables could reduce the rate of delayed extubation. It has also been demonstrated that delaying extubation increases the rate of VAP and alters the outcome. ${ }^{2}$ These data advocate for the development of new validated clinical rules to secure the process of extubation.

During neurologic recovery, it is very difficult to assess the exact level of consciousness in intubated patients with BI. Coplin et al. ${ }^{2}$ suggested that neurologic patients with mild impaired consciousness did not exhibit higher rates of extubation failures. Namen et al. ${ }^{17}$ advocated that a GCS of 8 could predict successful extubation in neurosurgical patients. 


\begin{tabular}{|c|c|c|c|}
\hline & $\begin{array}{l}\text { Extubation Success, } \\
\qquad N=338\end{array}$ & $\begin{array}{l}\text { Extubation Failure, } \\
\qquad N=99\end{array}$ & $P$ Value \\
\hline Unplanned extubation, n (\%) & $15(4.4)$ & $5(5.3)$ & $0.8^{*}$ \\
\hline Critical care withdrawal, n (\%) & $7(2.1)$ & $7(7.1)$ & $0.02^{*}$ \\
\hline $\begin{array}{l}\text { Duration of mechanical ventilation, median }\left(25^{\text {th }}-75^{\text {th }}\right. \\
\text { percentiles), } d\end{array}$ & $11(5-17)$ & $22(13-29)$ & $<0.0001 \dagger$ \\
\hline ICU length of stay, median ( $25^{\text {th }}-75^{\text {th }}$ percentiles), d & $15(9-23)$ & $27(21-36)$ & $<0.0001 \dagger$ \\
\hline In-ICU mortality, n (\%) & $4(1.2)$ & $11(11.1)$ & $<0.0001^{*}$ \\
\hline
\end{tabular}

Continuous data are expressed as median (25 th to $75^{\text {th }}$ percentiles) accordingly and tested with a paired $t$ test. Categoric data are expressed as $\mathrm{n}$ (\%) and tested with the Fisher test $\left(^{*}\right)$ or log-rank test $(\dagger) . P<0.05$.

$\mathrm{ICU}=$ intensive care unit.

Navalesi et al. ${ }^{14}$ randomized neurosurgical patients to test a strategy of early extubation when patients displayed a GSC of 8 or higher associated with audible cough. Altogether, these data reveal that full neurologic recovery is probably not mandatory to perform successful extubation. One critical surrogate marker of consciousness is visual pursuit, which can discriminate a minimally conscious state from vegetative state. ${ }^{18}$ Visual pursuit was also demonstrated to be a marker of good prognosis in minimally conscious states. ${ }^{19,20}$ Visual pursuit may be an earlier predictor than GCS for consciousness recovery. Also, due to the difficulty in properly assessing GCS in intubated patients because the verbal component is not available and must be extrapolated, we sought to use another tool for consciousness recovery. The present study shows that the presence of visual pursuit is an independent factor of extubation success in patients with BI. The eye subscale of the GCS was associated with success in univariate analysis but not multivariate analysis. All of the patients with their opened eyes bear the maximum subscale score of 4 , independent of their awareness in their environment. Other tests of cortical integration, such as visual pursuit, would enhance clinical examination. This could mainly explain why the eye subscale of the GCS was not associated with success in our cohort. Indeed, previous studies ${ }^{21,22}$ showed discrepancies regarding the level of arousal, that is, the ideal GCS to perform successful extubation. The main advantage of GCS is its widespread use, whereas its major drawback is the quantification of the verbal subscale. Additional studies should compare different scores regarding extubation in neuro-ICUs, which must include visual pursuit, because this parameter has been also pointed out by others. ${ }^{20}$ Because of the variability of GCS assessment, we have tested the clinical features of the VISAGE score in the subgroup of patients with a GCS less than 10. Age, visual pursuit, and swallowing attempts remained independent predictors of successful extubation (Supplemental Digital Content 5, http://links. lww.com/ALN/B493).

Impairment of airway reflexes due to neurologic dysfunction is considered to be a major factor for extubation failure in patients with BI. Swallowing dysfunction is common after BI, such as stroke ${ }^{23}$ or $\mathrm{TBI},{ }^{24}$ and may lead to nosocomial pneumonia. Swallowing dysfunction can be assessed with clinical tests or endoscopic technics, ${ }^{25}$ but this evaluation could be challenging in intubated patients. If swallowing attempts in intubated patients cannot guarantee the absence of aspiration, ${ }^{26}$ these attempts could also be a marker of early consciousness recovery, and studies have shown that patients with abundant secretions are more likely to have unsuccessful extubation. ${ }^{27,28}$ Our results are in line with these data. We did not monitor all aspects of endotracheal secretions, ${ }^{2}$ such as sputum aspects or sputum viscosity. In our study, the quantity of endotracheal secretions assessed by the necessity to perform endotracheal aspirates by the nurses per hour was not related to extubation success. We believe that an important quantity of secretions could have postponed extubation. Also, extubation was performed in the setting of limited endotracheal aspirates, and this may explain that the amount of secretions is not related to the outcome. Another fact explaining why secretions do not alter the outcome in the present results is that the ability of the patient to swallow limits the consequences of aspiration of endotracheal secretions. Cough has been advocated to be helpful in performing successful extubation. ${ }^{2,14}$ We decided to study cough in a binary approach and not to quantify it because of the risk of variability between centers. Second, cough could be irrelevant in the context of adequate swallowing, which could prevent aspiration despite ineffective cough. However, we are aware that this approach remains a subject of hard debate.

Age is the only nonmodifiable risk factor of the VISAGE score. Therefore, patients with an age greater than 40 yr should display all other items to have a high probability of extubation success. Age has already been pointed out as a risk factor for extubation failure in several studies. ${ }^{29-31}$ Considering these issues, the attending physician must be very cautious before performing extubation in neuro-ICU patients when age is above $40 \mathrm{yr}$.

The decision to reintubate in case of extubation failure is complex with neurologic patients. Indeed, the latest guidelines on $\mathrm{TBI}^{8}$ recommend intubation in the setting of a GCS of 8 or lower after injury. We withheld this threshold to standardize practices between centers, but usually the causes of reintubation are mixed, because neurologic impairment could lead to respiratory failure. The cause of extubation failure was therefore declarative. With growing evidence in the field of 
ICU regarding postextubation management with noninvasive ventilation and high flow oxygen nasal cannula, it is possible that monitoring extubation failure beyond the usual $48 \mathrm{~h}$ threshold is now of primary interest. However, prophylactic noninvasive ventilation was not used during the study period.

Our study has limitations. First, we do not have an external cohort to validate our score. In the setting of a multivariate analysis performed in a single cohort, extrapolating results in other centers is questionable. The validation cohort enables us to perform such extrapolations. Therefore, we cannot ascertain that others would retrieve the same results. Second, the VISAGE score bears low sensitivity, and only 194 patients (57\%) with a VISAGE score of 3 to 4 were successfully extubated. A VISAGE score of 1 to 2 could also delay extubation. Our score remains informative, with a value of 3 or 4 . The median GCS was similar in both groups, but our threshold seems to bear better clinical relevance (Supplemental Digital Content 4, http://links.lww.com/ ALN/B492). GCS alone cannot be used to predict extubation success, and the use of the overall score is mandatory. Fourth, our extubation failure incidence is in the range of previously published data. ${ }^{2,17,32,33}$ We believe that the relatively high incidence of extubation failure is not the consequence of an unsatisfactory weaning protocol but rather highlights the challenging issue of extubation in patients with BI. Fifth, there is little evidence regarding sedation management after BI. Indeed, sedation is usually prolonged with important doses of sedative drugs in neuro-ICU centers, ${ }^{9}$ and this could interfere with the extubation process. The onset of late VAP between successful SBT and extubation was not recorded. This aspect was already underlined by Coplin et al., ${ }^{2}$ and enhancing successful extubation in this population could drastically decrease the rate of late VAP. Also, we did not record early episodes of VAP, which could alter the outcome. In our study, we did not focus on delay between the first passed SBT and extubation, which was already pointed out by Coplin et al. ${ }^{2}$ Gag reflex has been studied previously, ${ }^{2,21}$ and we did not evaluate this parameter. Fluid balance has been identified as a marker of success in this subset of patients, ${ }^{34}$ but we did not assess this factor in our study. Eventually, we did not monitor long-term outcome. We cannot ascertain that extubation failure bears no consequences on long-term neurologic recovery.

In this work, we provide substantial data for the extubation management of neuro-ICU patients. We found that the rate of extubation success, after passing an SBT, is high in patients with BI with at least three criteria on the VISAGE score: age less than $40 \mathrm{yr}$, visual pursuit, swallowing, and GCS greater than 10 . Our score was not validated on an external cohort, and our results should be evaluated in other centers.

\section{Acknowledgments}

The authors thank the nurses, physiotherapists, research assistants, residents, and attending doctors of all participating ICUs (Réanimation chirurgicale CHU Angers, Réanimation chirurgicale Hôtel Dieu et Hôpital Laennec CHU Nantes, and Réanimation chirurgicale CHU Rennes) for their help in performing this work.

\section{Research Support}

Support was provided solely from institutional and/or departmental sources.

\section{Competing Interests}

The authors declare no competing interests.

\section{Correspondence}

Address correspondence to Dr. Asehnoune: Department of Anesthesia and Critical Care, Hôtel Dieu, 1 Place Alexis Ricordeau, 44093 Nantes Cedex 9, France. karim.asehnoune@ chu-nantes.fr. Information on purchasing reprints may be found at www.anesthesiology.org or on the masthead page at the beginning of this issue. Anesthesiology's articles are made freely accessible to all readers, for personal use only, 6 months from the cover date of the issue.

\section{References}

1. Roquilly A, Cinotti R, Jaber S, Vourc'h M, Pengam F, Mahe PJ, Lakhal K, Demeure Dit Latte D, Rondeau N, Loutrel O, Paulus J, Rozec B, Blanloeil Y, Vibet MA, Sebille V, Feuillet $\mathrm{F}$, Asehnoune K: Implementation of an evidence-based extubation readiness bundle in 499 brain-injured patients: A before-after evaluation of a quality improvement project. Am J Respir Crit Care Med 2013; 188:958-66

2. Coplin WM, Pierson DJ, Cooley KD, Newell DW, Rubenfeld GD: Implications of extubation delay in brain-injured patients meeting standard weaning criteria. Am J Respir Crit Care Med 2000; 161:1530-6

3. Boles JM, Bion J, Connors A, Herridge M, Marsh B, Melot C, Pearl R, Silverman H, Stanchina M, Vieillard-Baron A, Welte T: Weaning from mechanical ventilation. Eur Respir J 2007; 29:1033-56

4. Asehnoune K, Mrozek S, Perrigault PF, Seguin P, DahyotFizelier C, Lasocki S, Pujol A, Martin M, Chabanne R, Muller L, Hanouz JL, Hammad E, Rozec B, Kerforne T, Ichai C, Cinotti R, Geeraerts T, Elaroussi D, Pelosi P, Jaber S, Dalichampt M, Feuillet F, Sébille V, Roquilly A, BI-VILI study group: A multi-faceted strategy to reduce ventilation-associated mortality in brain-injured patients. The BI-VILI project: a nationwide quality improvement project. Intensive Care Med 2017; 287:345-14

5. Collins GS, Reitsma JB, Altman DG, Moons KG: Transparent reporting of a multivariable prediction model for individual prognosis or diagnosis (TRIPOD): The TRIPOD statement. Ann Intern Med 2015; 162:55-63

6. Stocchetti N, Maas AI: Traumatic intracranial hypertension. N Engl J Med 2014; 370:2121-30

7. Connolly ES Jr, Rabinstein AA, Carhuapoma JR, Derdeyn CP, Dion J, Higashida RT, Hoh BL, Kirkness CJ, Naidech AM, Ogilvy CS, Patel AB, Thompson BG, Vespa P; American Heart Association Stroke Council; Council on Cardiovascular Radiology and Intervention; Council on Cardiovascular Nursing; Council on Cardiovascular Surgery and Anesthesia; Council on Clinical Cardiology: Guidelines for the management of aneurysmal subarachnoid hemorrhage: A guideline for healthcare professionals from the American Heart Association/ american Stroke Association. Stroke 2012; 43:1711-37

8. Brain Trauma Foundation, American Association of Neurological Surgeons, Congress of Neurological Surgeons: Guidelines for the management of severe traumatic brain injury. J Neurotrauma 2007; 24(suppl 1):S1-106 
9. Antonelli M, Bonten M, Cecconi M, Chastre J, Citerio G, Conti G, Curtis JR, Hedenstierna G, Joannidis M, Macrae D, Maggiore SM, Mancebo J, Mebazaa A, Preiser JC, Rocco P, Timsit JF, Wernerman J, Zhang H: Year in review in Intensive Care Medicine 2012: I-Neurology and neurointensive care, epidemiology and nephrology, biomarkers and inflammation, nutrition, experimentals. Intensive Care Med 2013; 39:232-46

10. Roquilly A, Mahe PJ, Latte DD, Loutrel O, Champin P, Di Falco C, Courbe A, Buffenoir K, Hamel O, Lejus C, Sebille V, Asehnoune K: Continuous controlled-infusion of hypertonic saline solution in traumatic brain-injured patients: A 9-year retrospective study. Crit Care 2011; 15:R260

11. Roquilly A, Feuillet F, Seguin P, Lasocki S, Cinotti R, Launey Y, Thioliere L, Le Floch R, Mahe PJ, Nesseler N, Cazaubiel T, Rozec B, Lepelletier D, Sebille V, Malledant Y, Asehnoune K; ATLANREA group: Empiric antimicrobial therapy for ventilator-associated pneumonia after brain injury. Eur Respir J 2016; 47:1219-28

12. Helbok R, Kurtz P, Schmidt MJ, Stuart MR, Fernandez L, Connolly SE, Lee K, Schmutzhard E, Mayer SA, Claassen J, Badjatia N: Effects of the neurological wake-up test on clinical examination, intracranial pressure, brain metabolism and brain tissue oxygenation in severely brain-injured patients. Crit Care 2012; 16:R226

13. Kreymann KG, Berger MM, Deutz NE, Hiesmayr M, Jolliet P, Kazandjiev G, Nitenberg G, van den Berghe G, Wernerman J, Ebner C, Hartl W, Heymann C, Spies C; DGEM (German Society for Nutritional Medicine); ESPEN (European Society for Parenteral and Enteral Nutrition): ESPEN guidelines on enteral nutrition: Intensive care. Clin Nutr 2006; 25:210-23

14. Navalesi P, Frigerio P, Moretti MP, Sommariva M, Vesconi S, Baiardi P, Levati A: Rate of reintubation in mechanically ventilated neurosurgical and neurologic patients: Evaluation of a systematic approach to weaning and extubation. Crit Care Med 2008; 36:2986-92

15. Steyerberg EW, Harrell FE Jr, Borsboom GJ, Eijkemans MJ, Vergouwe Y, Habbema JD: Internal validation of predictive models: Efficiency of some procedures for logistic regression analysis. J Clin Epidemiol 2001; 54:774-81

16. Fitzgerald M, Saville BR, Lewis RJ: Decision curve analysis. JAMA 2015; 313:409-10

17. Namen AM, Ely EW, Tatter SB, Case LD, Lucia MA, Smith A, Landry S, Wilson JA, Glazier SS, Branch CL, Kelly DL, Bowton DL, Haponik EF: Predictors of successful extubation in neurosurgical patients. Am J Respir Crit Care Med 2001; 163(3 pt 1):658-64

18. Giacino JT, Ashwal S, Childs N, Cranford R, Jennett B, Katz DI, Kelly JP, Rosenberg JH, Whyte J, Zafonte RD, Zasler ND: The minimally conscious state: Definition and diagnostic criteria. Neurology 2002; 58:349-53

19. Giacino J, Kalmar K: Diagnostic and prognostic guidelines for the vegetative and minimally conscious states. Neuropsychol Rehabil 2005; 15:166-74

20. Riganello F, Cortese MD, Dolce G, Sannita WG: Visual pursuit response in the severe disorder of consciousness: Modulation by the central autonomic system and a predictive model. BMC Neurol 2013; 13:164

21. Godet $T$, Chabanne R, Marin J, Kauffmann S, Futier E, Pereira B, Constantin J-M: Extubation failure in brain-injured patients: Risk factors and development of a prediction score in a preliminary prospective cohort study. ANESTHESIOLOGY 2017; 126:104-14

22. Anderson CD, Bartscher JF, Scripko PD, Biffi A, Chase D, Guanci M, Greer DM: Neurologic examination and extubation outcome in the neurocritical care unit. Neurocrit Care 2011; 15:490-7

23. Martino R, Foley N, Bhogal S, Diamant N, Speechley M, Teasell R: Dysphagia after stroke: Incidence, diagnosis, and pulmonary complications. Stroke 2005; 36:2756-63

24. Mandaville A, Ray A, Robertson H, Foster C, Jesser C: A retrospective review of swallow dysfunction in patients with severe traumatic brain injury. Dysphagia 2014; 29:310-8

25. Warnecke T, Suntrup S, Teismann IK, Hamacher C, Oelenberg S, Dziewas R: Standardized endoscopic swallowing evaluation for tracheostomy decannulation in critically ill neurologic patients. Crit Care Med 2013; 41:1728-32

26. Nseir S, Zerimech F, Fournier C, Lubret R, Ramon P, Durocher A, Balduyck M: Continuous control of tracheal cuff pressure and microaspiration of gastric contents in critically ill patients. Am J Respir Crit Care Med 2011; 184:1041-7

27. Salam A, Tilluckdharry L, Amoateng-Adjepong Y, Manthous CA: Neurologic status, cough, secretions and extubation outcomes. Intensive Care Med 2004; 30:1334-9

28. Khamiees M, Raju P, DeGirolamo A, Amoateng-Adjepong Y, Manthous CA: Predictors of extubation outcome in patients who have successfully completed a spontaneous breathing trial. Chest 2001; 120:1262-70

29. Thille AW, Harrois A, Schortgen F, Brun-Buisson C, Brochard L: Outcomes of extubation failure in medical intensive care unit patients. Crit Care Med 2011; 39:2612-8

30. Thille AW, Boissier F, Ben Ghezala H, Razazi K, MekontsoDessap A, Brun-Buisson C: Risk factors for and prediction by caregivers of extubation failure in ICU patients: A prospective study. Crit Care Med 2015; 43:613-20

31. Frutos-Vivar F, Ferguson ND, Esteban A, Epstein SK, Arabi Y, Apezteguía C, González M, Hill NS, Nava S, D'Empaire G, Anzueto A: Risk factors for extubation failure in patients following a successful spontaneous breathing trial. Chest 2006; 130:1664-71

32. Koh WY, Lew TW, Chin NM, Wong MF: Tracheostomy in a neuro-intensive care setting: Indications and timing. Anaesth Intensive Care 1997; 25:365-8

33. Vallverdú I, Calaf N, Subirana M, Net A, Benito S, Mancebo $\mathrm{J}$ : Clinical characteristics, respiratory functional parameters, and outcome of a two-hour T-piece trial in patients weaning from mechanical ventilation. Am J Respir Crit Care Med 1998; 158:1855-62

34. McCredie VA, Ferguson ND, Pinto RL, Adhikari NK, Fowler RA, Chapman MG, Burrell A, Baker AJ, Cook DJ, Meade MO, Scales DC; Canadian Critical Care Trials Group: Airway management strategies for brain-injured patients meeting standard criteria to consider extubation: A prospective cohort study. Ann Am Thorac Soc 2017; 14:85-93

\section{Appendix}

Team members of the ATLANREA group (in alphabetical order) include Karim Asehnoune, M.D., Ph.D., Yvonnick Blanloeil, M.D., Ph.D., Raphaël Cinotti, M.D., Adrien Delater, M.D., Florian Denou, M.D., Dominique Deumeure-dit-Latte, M.D., Antoine Gros, M.D., Karim Lakhal, M.D., Sigismond Lasocki, M.D., Ph.D., Yoann Launey, M.D., Pierre-Joachim Mahé, M.D., Yannick Mallédant, M.D., Ph.D., Nicolas Nesseler, M.D., Antoine Roquilly, M.D., Bertrand Rozec, M.D., Ph.D., Philippe Seguin, M.D., Ph.D. 